\title{
Adults with Housing Insecurity Have Worse Access to Primary and Preventive Care
}

\author{
Patricia Martin, DO, Winston Liaw, MD, MPH, Andrew Bazemore, MD, MPH, \\ Anuradha Jetty, MPH, Stephen Petterson, PhD, and Margot Kushel, MD
}

Objective: Housing insecurity has been linked to high-risk behaviors and chronic disease, although less is known about the pathways leading to poor health. We sought to determine whether housing insecurity is associated with access to preventive and primary care.

Methods: We conducted weighted univariate, bivariate, and multivariate analyses by using 2011 to 2015 Behavioral Risk factor Surveillance Survey data $(\mathrm{N}=\mathbf{2 2 8 , 1 3 1}$ adults $)$. The independent variable was housing insecurity derived from the question on worry about paying rent or mortgage. The outcome measures were health services utilization (no usual source of care, no routine checkup in the past 1 year, and delayed medical care due to cost), self-rated health (number of days reported physical, mental health not good, and poor overall health), and number of chronic diseases ( $0,1,2$ or more). The covariates included age, sex, race/ethnicity, income, level of education, marital status, and number of children in the family. We also adjusted for state fixed effects and survey year. We performed $\chi^{2}$ tests and binary logistic regressions on categorical variables and ran $t$ tests and estimated linear regression models on continuous variables. Multinomial logistic regressions were estimated for the number of chronic diseases.

Results: Of the 228,131 adults in the study sample, 28,704 adults reported housing insecurity. We found that those with housing insecurity were more likely to forgo routine check-ups and lack usual sources of care. Low-income individuals, minorities, the unmarried, and middle-aged adults were more likely to report housing insecurity.

Conclusion: Housing insecurity is associated with worse access to preventive and primary care. Interventions to enhance access for these patients should be developed and studied. (J Am Board Fam Med 2019;32:521-530.)

Keywords: Behavioral Risk Factor, Chronic Disease, Homeless Persons, Housing, Linear Models, Logistic Models, Mental Health, Multivariate Analysis, Outcomes Assessment, Primary Health Care, Risk-Taking, Social Determinants of Health, Surveillance System

Social determinants of health (SDH) have a greater impact on people's health and longevity than clinical care ${ }^{1}$ and addressing these determinants is viewed as a key strategy for meeting the triple aim of lower costs, improved patient experience, and improved population health. Although numerous

This article was externally peer reviewed.

Submitted 15 December 2018; revised 26 March 2019; accepted 31 March 2019.

From Unity Health Care, Washington, D.C. (PM); Department of Health Systems and Population Health Sciences, University of Houston College of Medicine, Houston (WL); Robert Graham Center: Policy Studies in Family Medicine and Primary Care, Washington D.C. (AB, AJ, SP); Center for Vulnerable Populations, University of California, San Francisco/Zuckerberg San Francisco General, San Francisco (MK). organizations have called for the integration of public health and primary care to address SDH, operationalizing the integration of data has proven difficult, with uncertainty around the types of data to collect to improve outcomes. ${ }^{2,3}$

Housing insecurity is likely the SDH with the largest potential impact on population health, if properly addressed. Defining housing insecurity can be challenging as it refers to a spectrum of housing experiences, including homelessness, crowding, high

Funding: none.

Conflict of interest: none declared.

Corresponding author: Patricia Martin, DO, Unity Health Care, Washington, D.C. (E-mail: pmartin@unityhealthcare.org). 
housing costs in proportion to income (defined variably as $\geq 30 \%$ and $\geq 50 \%$ of household income), foreclosure, and frequent moves. ${ }^{4,5}$ Despite disagreement about the definition, housing insecurity affects millions of Americans, with over 21 million paying $30 \%$ to $50 \%$ and nearly 19 million households paying more than $50 \%$ of their income in housing costs. ${ }^{6}$

The independent association between housing insecurity and poor health has been well-documented for both adults and children over the past 30 years. ${ }^{5,7-10}$ Nationally, we found a graded association between degree of housing insecurity and decreased access to care. ${ }^{7}$ Adults experiencing homelessness reported higher rates of acute care services, such as emergency department visits, as well as postponement of needed medical care and medications. ${ }^{5}$ Housing instability and frequent moves affect children in similar ways, resulting in increased use of acute care services, ${ }^{11,12}$ postponement of needed care, ${ }^{11}$ and lack of a regular site for preventive care. ${ }^{12}$ The prevalence of housing insecurity among low-income children (defined as living $<200 \%$ below the federal poverty line or lacking commercial health insurance coverage) ranges from $29.5 \%{ }^{11}$ to $46 \%$ respectively. ${ }^{13}$ There are long-term health outcomes associated with childhood housing insecurity, which include earlier use of illicit drugs,${ }^{14,15}$ increased rates of depression and pregnancy among teenagers, ${ }^{15}$ and poor emotional adjustment. $^{15}$

Despite housing insecurity's impact on health outcomes, researchers and policy makers have not achieved consensus around its measurement. Several clinically validated screening questions in use by organizations such as Children's Health Watch and the Veteran's Administration. ${ }^{16}$ The Centers for Disease Control and Prevention Behavioral Risk Factor Surveillance Survey (BRFSS) has included a question regarding housing insecurity since 2009. ${ }^{17}$ Deemed to be written at a 12 th grade reading level with adequate precision and clinical validity, ${ }^{16}$ the question asks, "How often in the past 12 months would you say that you were worried or stressed about having enough money to pay your rent/mortgage?"17 The question addresses perceived stress rather than a specific housing-related metric, such as percent of household income spent on housing. Perceived stress, however, offers a highly sensitive screening tool with the opportunity to capture the highest number of individuals at risk for becoming homeless. Furthermore, less is known about the relationship between housing insecurity and preventive and primary care access. In particular, having a usual source of care (USOC, or a singular person or facility for navigating most health care needs) is critical to receiving the recommended screening tests and preventive services that can delay or prevent the development of chronic disease. ${ }^{18}$ Our objective was to determine how this BRFSS housing insecurity assessment was associated with preventive and primary care access, self-rated health, and chronic disease.

\section{Methods}

We obtained data from the 2011 to 2015 BRFSS. The BRFSS is a phone-based survey that collects data regarding health-related risk behaviors, chronic health conditions, and health services utilization. It is administered annually to noninstitutionalized adults over the age of 18 in all 50 US states, Washington D.C., and 3 US territories. ${ }^{17}$

The BRFSS is composed of standard core questions, rotating core questions, optional modules, and state-based questions. Standard core questions are asked every year; whereas, rotating core questions are asked every other year. States may also select to include optional BRFSS modules as well as additional state-specific questions. ${ }^{19}$

The Social Context Module is an optional module that focuses on housing insecurity, food insecurity, and employment. We included all 23 states that incorporated this module into their BRFSS questionnaires at any point between 2011 and 2015. For the states included, the sample population was comparable to the population not included in the sample (Supplemental Table 1), although the sample population was noted to be older, more affluent, and have a lower proportion of Hispanics. The survey includes both landline and cell phone respondents from 2011 onwards. Response rates for landline and cell phone users were $53.0 \%$ and $27.9 \%$ (2011), $49.1 \%$ and $35.5 \%$ (2012), $49.6 \%$ and $37.8 \%$ (2013), $48.7 \%$ and $40.5 \%$ (2014), and $47.7 \%$ and $39.5 \%$ (2015), respectively.

We determined the presence of housing insecurity based on the question, "How often in the past 12 months would you say that you were worried or stressed about having enough money to pay your rent/mortgage?" Responses included the following: always, usually, sometimes, rarely, and never. We deemed the affirmative responses "always" and 
"usually" as markers for housing insecurity and dichotomized the sample based on the presence or absence of housing insecurity.

The covariates included age, sex, race/ethnicity, income, level of education, marital status, number of children, and health status. We created 6 mutually exclusive age brackets ( 18 to 24,25 to 34,35 to 44,45 to 54,55 to 64 , and $65+$ ) and 2 mutually exclusive sex self-identifiers. The race/ethnicity categories were white, black, Hispanic, and other. We stratified income levels in 4 brackets based on household income less than $\$ 15,000, \$ 15,000$ or more and less than $\$ 25,000, \$ 25,000$ or more and less than $\$ 50,000$, and $\$ 50,000$ or more. We classified level of education in 4 mutually exclusive groups: less than high school education, high school graduate/general education degree, some college or technical school (1 to 3 years), and 4 years or more of college education. Self-reported health status was classified as excellent, very good, good, fair, or poor. Finally, to assess family structure, we determined the number of children and marital status (married, divorced, widowed, separated, never married, and unmarried with partner).

The dependent variables can be grouped into 3 categories: (1) health services utilization, (2) selfreported health status, and (3) presence of chronic medical conditions. For health services utilization, we assessed the respondents' USOC status, deferment of medical care due to cost, and prolonged time since last medical checkup. We characterized absence of a USOC by a "No" response to the question "Do you have 1 person that you think of as your personal doctor or health care provider?" We characterized deferment of medical care due to cost as a "Yes" response to the question "Was there a time in the past 12 months when you needed to see a doctor but could not because of cost?" Lastly, we characterized prolonged time since last medical checkup as any response other than "Within the past year" to the question "About how long has it been since you last visited a doctor for a routine checkup?"

The second and third categories of interest were self-reported health and the presence of chronic medical conditions. We assessed self-reported health by determining the responses to 3 questions that inquire about the specific number of days within the past month that physical, mental, and overall health were not good. The presence of chronic medical conditions is also by self-report.
Respondents are asked about several different health conditions with the following common question stem: "Have you ever been told by a doctor, nurse, or health care professional that you have had any of the following?" Diabetes, hypertension, coronary artery disease, stroke, chronic obstructive pulmonary disease/asthma, skin cancer, other cancer, arthritis, depression, and chronic kidney disease were among the included conditions. Those reporting skin cancer or other cancer were grouped as any cancer. We created 3 chronic disease categories: (1) no chronic conditions, (2) 1 chronic condition, and (3) 2 or more chronic conditions.

\section{Statistical Analysis}

Using Stata 14.0, we conducted univariate and bivariate $\left(\chi^{2}\right.$ for categorical variables and $t$ tests for continuous variables) analyses and multivariate linear and binary logistic regressions. We used sampling weights and BRFSS survey design variables throughout the analysis to obtain a nationally representative sample of undersampled populations. We first compared the demographic characteristics (sex, age, education, race/ethnicity, and poverty) of the respondents in sample and out of sample by conducting bivariate analysis using $\chi^{2}$ tests for categorical and $t$ tests for continuous variables. For the respondents in the sample, we then computed descriptive statistics of demographic characteristics and conducted bivariate analyses by housing insecurity. We estimated 3 sets of regression models by using linear regression for continuous outcomes (health status measures reported as number of days) and logistic regressions for binary outcomes (having a USOC, avoiding or delaying medical care, and having a chronic medical condition). In all the models, we used housing insecurity as an independent variable and patient characteristics as covariates. Because our analysis was restricted to a publicly available data set, institutional review board approval was neither required nor obtained.

\section{Results}

Of the 228,131 individuals in our sample, $14.3 \%$ reported housing insecurity (Supplemental Table 2). Those reporting housing insecurity were more likely to be female, have lower incomes, and be black or Hispanic. Of all age groups, middle-age adults (35 to 54) were the most likely to experience housing insecurity. As expected, those with a college 


\begin{tabular}{|c|c|c|c|c|c|}
\hline \multirow[b]{3}{*}{ Self-Reported Health Status and Utilization } & \multicolumn{5}{|c|}{ Worry About Paying Rent or Mortgage } \\
\hline & \multicolumn{2}{|c|}{ Yes $(n=28,704)$} & \multicolumn{2}{|c|}{ No $(\mathrm{n}=199,427)$} & \multirow[b]{2}{*}{$P$ Value } \\
\hline & $\mathrm{n}$ & $\%$ & $\mathrm{n}$ & $\%$ & \\
\hline \multicolumn{6}{|l|}{ Number of Chronic Conditions } \\
\hline 0 & 910 & 30.8 & 10,984 & 43.5 & $<.001$ \\
\hline 1 & 919 & 27.7 & 8,620 & 26 & .6397 \\
\hline 2 or more & 1,973 & 41.5 & 12,312 & 30.4 & $<.001$ \\
\hline \multicolumn{6}{|l|}{ Health services utilization } \\
\hline Deferred care due to cost & 11,009 & 42.8 & 14,899 & 10.2 & $<.001$ \\
\hline Had a routine check-up within past year & 18,821 & 64.0 & 148,768 & 73.8 & $<.001$ \\
\hline No usual source of care & 6,168 & 29.0 & 26,682 & 19.4 & $<.001$ \\
\hline \multicolumn{6}{|l|}{$\begin{array}{l}\text { Self-reported health (mean number of days } \\
\text { in last month) }\end{array}$} \\
\hline Poor physical health & 8.6 & & 3.9 & & $<.001$ \\
\hline Poor mental health & 9.5 & & 2.6 & & $<.001$ \\
\hline Poor overall health & 8.0 & & 3.3 & & $<.001$ \\
\hline
\end{tabular}

Source: Author analysis of 2011 to 2015 Behavioral Risk Factor Surveillance Survey (BRFSS) data. Between 2011 to 2015,23 states implemented the Social Context Module that included this question. BRFSS asks about self-reported health by determining the responses to three questions that inquire about the specific number of days within the past month that physical, mental, and overall health were not good.

education were less likely to be housing insecure. Those with more than a high school education were also less likely to be housing insecure, which may reflect individuals living in areas with a high cost-ofliving who despite reported income of $>\$ 50,000$ are still uncomfortable with their disproportionate housing costs. Not being married, having larger families, and being in poor health were all associated with housing insecurity.

Those with housing insecurity were more likely to report chronic diseases, lack a USOC, and defer care in the past year due to cost (Table 1). With respect to overall health, those with housing insecurity had more days in the last month with poor health. Furthermore, the number of days in poor mental health was the highest of the 3 health categories.

After controlling for covariates, we found that those with housing insecurity had 3 times higher odds of delaying care due to cost. Housing-insecure respondents also had $35 \%$ higher odds of delaying check-ups and had 19\% higher odds of lacking a USOC. In our second regression model, where the outcome was number of days in poor health, we found that housing insecurity was associated with 4.7 more days in poor physical health, 6.9 more days in poor mental health, and 4.7 more days in poor overall health. In our final regression model, relative to those with no chronic conditions, we found that those with housing insecurity were more likely to have 1 or more chronic conditions.

\section{Discussion}

BRFSS has been widely used to demonstrate the association between housing insecurity and health outcomes at the single-state level ${ }^{9,20-22}$ as well as the multistate level ${ }^{23-27}$ although none of these studies assessed housing insecurity's impact on preventive and primary care access. Our findings confirm the potent relationship between housing insecurity and poor health and add to the literature by documenting that, among those with housing insecurity, poor health may be the consequence of forgoing routine care and lacking a USOC. Furthermore, we found that low-income, minority, unmarried, middle-aged adults are more likely to report housing insecurity. As public health and primary care collaborate to identify and address housing insecurity, these findings can provide guidance for future screening efforts, such as whether to use targeted or universal screening for housing insecurity.

There are 1-item screening tools already in use by other agencies, such as Children's Health Watch ("An eviction is when your landlord or a government or bank official forces you to move when you do not want to. In the past 5 years, have 
you ever been evicted?") and the Veterans Administration ("Are you worried or concerned that in the next 2 months you may not have stable housing that you own, rent, or stay in as part of a household?"). The populations of interest for these agencies, however, are not reflective of the general population, limiting their generalizability.

In 2017, the Center for Medicaid and Medicare Services also released the 10-item Accountable Health Communities Screening Tool, which includes 2 items relating to housing insecurity ("What is your housing situation today?" and "Think about the place where you live. Do you have problems with any of the following? Bug Infestation, Mold, Lead Paint or Pipes, Inadequate Heat, Oven of Stove Not Working, No or Not Working Smoke Detectors, Water Leaks"). ${ }^{28}$ The first question was adapted from the Protocol for Responding to and Addressing Patients' Assets, Risks, and Experiences assessment tool. ${ }^{29}$ The second question was drawn from a screening tool developed by Norwalk Community Health Center to capture patients that would benefit from legal services offered by their medical-legal partnership. ${ }^{31}$ These items are evidence-based but have not yet been validated. ${ }^{28}$ In addition, given the recent development of the Center for Medicaid and Medicare Services screening tool, there are no available studies at this time to link these particular housing insecurity items with health-related outcomes.

Housing insecurity was omitted as a National Academy of Medicine-recommended domain for inclusion in electronic health records as part of Meaningful Use because of the lack of standard measure and perceived difficulty in collecting housing insecurity data. ${ }^{4,5}$ Without a standard housing insecurity metric, there is a need for a validated screening tool for the general population to begin collecting and appropriately acting on this SDH data. Our findings add to the existing literature supporting the use of this BRFSS housing insecurity question. In the absence of systematic assessment of housing within medicine, this critical SDH will continue to be ignored by clinicians and linkages between medicine and public health will fail to develop.

With appropriate screening, those with housing insecurity can be identified and referred for assistance. The role of primary care providers in the implementation of interventions to address SDH is evolving. Thus far, generating referrals for existing community resources and following up with parents has proven beneficial in the pediatric settings. ${ }^{31,32}$ Among the adult population, pilot studies like the WellRx in New Mexico have drawn attention to the important role of community health workers in helping patients with unmet social needs to follow through and successfully access community resources. ${ }^{33}$ Medical-legal partnerships also have a role in the primary care setting in addressing unmet social needs that involve the legal system and have been successful in many patient center medical home settings. ${ }^{34}$

Although the demand for stable affordable housing in the United States far outpaces the limited supply, there is still benefit to screening for SDH in primary care. Having information about patients' unmet social needs can improve patient care by better informing providers, who can engage patients in discussions that would not otherwise occur $^{34}$ and advocate on their behalf for interventions at the community level, including enhancing access to housing voucher programs and programs that prevent evictions and building high-quality, lowincome housing within mixed-income neighborhoods.

Even the briefest SDH screening tool, however, requires time and investment on the part of providers. For providers who are not working directly with a social worker, referrals for community resources and follow up may fall to the provider. Although these efforts may result in improved health outcomes and health care cost savings, it is unclear how that cost savings would be shared. More work is needed to explore how primary care practices could be appropriately compensated for the increased expenditure of time and staff resources spent in deploying screening for housing insecurity.

Some limitations to the data source used in our analyses are worth noting, including sampling that is not nationally representative, reflecting only the states that administered the BRFSS Social Context Module. As noted earlier, the housing insecurity question addresses self-reported stress regarding paying rent or a mortgage, which is subject to survey participant interpretation of both the definition of stress as well as their own stress level. Dependent variables were also based on self-report, and the survey questions asked about behaviors over different time periods. For example, the question regarding housing insecurity includes the past 
12 months while the questions regarding self-reported health included the past 30 days and the questions regarding health care utilization go back as far as 5 years. Finally, BRFSS is a phone-based survey that excludes institutionalized adults, which omits those without phone lines as well as those living in shelters, transitional housing, or outside. It is unclear how inclusion of these populations would impact our findings. The BRFSS question is oriented toward those paying rent or a mortgage, so institutionalized individuals or individuals living in shelters, transitional housing, or outside may not be captured as experiencing housing insecurity.

In summary, housing insecurity is associated with poor health, chronic disease, and inefficiently delivered care and is should be considered when conducting social need assessments in high-risk clinical settings or for incorporation into community vital signs. Future research will need to determine those populations that will most benefit from screening. Clinicians and public health practitioners will need to identify effective pathways for connecting individuals to community resources and scale effective community interventions.

To see this article online, please go to: http://jabfm.org/content/ 32/4/521.full.

\section{References}

1. Bachrach D, Pfister H, Wallis K, Lipson M. Addressing patients' social needs. 2014. Available from: http://www.manatt.com/uploadedFiles/Content/5 News_and_Events/Newsletters/Medicaid_Update/ Addressing-Patients-Social-Needs-An-EmergingBusiness-Case-for-Provider-Investment.pdf. Accessed September 24, 2016.

2. Gottlieb LM, Tirozzi KJ, Manchanda R, Burns AR, Sandel MT. Moving electronic medical records upstream. Am J Prev Med 2015;48:215-8.

3. DeVoe JE, Bazemore AW, Cottrell EK, et al. Perspectives in primary care: a conceptual framework and path for integrating social determinants of health into primary care practice. Ann Fam Med 2016;14:104-8.

4. Committee on the Recommended Social and Behavioral Domains and Measures for Electronic Health Records, Board on Population Health and Public Health Practice, Institute of Medicine. Capturing Social and Behavioral Domains and Measures in Electronic Health Records: Phase 2. Washington, D.C.: National Academies Press; 2014. Available from: http://www.nap.edu/catalog/18951. Accessed September 24, 2016.

5. Kushel MB, Gupta R, Gee L, Haas JS. Housing instability and food insecurity as barriers to health care among low-income Americans. J Gen Intern Med 2006;21:71-7.

6. The State of the Nation's Housing 2016. President and Fellows of Harvard College; 2016. Available from: https://www.jchs.harvard.edu/sites/default/files/ jchs_2016_state_of_the_nations_housing_lowres_0.pdf.

7. Reid KW, Vittinghoff E, Kushel MB. Association between the level of housing instability, economic standing and health care access: a meta-regression. J Health Care Poor Underserved 2008;19:1212-28.

8. Burgard SA, Seefeldt KS, Zelner S. Housing instability and health: Findings from the Michigan recession and recovery study. Soc Sci Med 2012; 75:2215-24.

9. Stahre M, VanEenwyk J, Siegel P, Njai R. Housing insecurity and the association with health outcomes and unhealthy behaviors, Washington State, 2011. Prev Chronic Dis 2015;12.

10. Pollack CE, Griffin BA, Lynch J. Housing affordability and health among homeowners and renters. Am J Prev Med 2010;39:515-21.

11. Ma CT, Gee L, Kushel MB. Associations between housing instability and food insecurity with health care access in low-income children. Ambul Pediatr 2008;8:50-7.

12. Fowler MG, Simpson GA, Schoendorf KC. Families on the move and children's health care. Pediatrics 1993;91:934-40.

13. Cutts DB, Meyers AF, Black MM, et al. US housing insecurity and the health of very young children. Am J Public Health 2011;101:1508-14.

14. DeWit DJ. Frequent childhood geographic relocation: Its impact on drug use initiation and the development of alcohol and other drug-related problems among adolescents and young adults. Addict Behav 1998;23:623-34.

15. Jelleyman T, Spencer N. Residential mobility in childhood and health outcomes: a systematic review. J Epidemiol Community Health 2008;62:584-92 .

16. Social Needs Screening Toolkit. HealthLeadsUSA.org; 2016. Available from: https://nopren.org/wp-content/ uploads/2016/12/Health-Leads-Screening-Toolkit-July2016.pdf.

17. Centers for Disease Control and Prevention (CDC). Behavioral Risk Factor Surveillance System Survey Questionnaire. Atlanta, Georgia: U.S. Department of Health and Human Services, Centers for Disease Control and Prevention, 2009.

18. DeVoe JE, Fryer GE, Phillips R, Green L. Receipt of preventive care among adults: insurance status and usual source of care. Am J Public Health 2003;93:786-91.

19. The Behavioral Risk Factor Surveillance System User Guide. Behavioral Risk Factor Surveillance Survey; 2013. Available from: https://www.cdc.gov/brfss/data_ documentation/pdf/UserguideJune2013.pdf.

20. Bossarte R, Blosnich J, Piegari R, Hill L, Kane V. Housing instability and mental distress among US veterans. Am J Public Health 2013;103:S211S212. 
21. Herrick H, Vito Di Bona MS. The Association of Housing Stress, Health, Chronic Disease and Health Care Resources: Results from the 2011 North Carolina BRFSS Survey. Citeseer; 2013. Available from: http://citeseerx.ist.psu.edu/viewdoc/download? doi $=10.1 .1 .446 .2110 \&$ rep $=$ rep $1 \&$ type $=$ pdf. Accessed August 18, 2016.

22. Pobutsky AM, Baker KK, Reyes-Salvail F. Investigating measures of social context on 2 populationbased health surveys, Hawaii, 2010-2012. Prev Chronic Dis 2015;12:E221.

23. Charkhchi P, Fazeli Dehkordy S, Carlos RC. Housing and food insecurity, care access, and health status among the chronically ill: an analysis of the behavioral risk factor surveillance system. J Gen Intern Med 2018;33:644-50.

24. Charters TJ, Harper S, Strumpf EC, Subramanian SV, Arcaya M, Nandi A. The effect of metropolitanarea mortgage delinquency on health behaviors, access to health services, and self-rated health in the United States, 2003-2010. Soc Sci Med 2016;161: 74-82.

25. Schure MB, Katon JG, Wong E, Liu C-F. Food and housing insecurity and health status among U.S. adults with and without prior military service. SSM Popul Health 2016;2:244-8.

26. Njai R, Siegel P, Yin S, Liao Y. Prevalence of perceived food and housing security - 15 states, 2013. MMWR Morb Mortal Wkly Rep 2017;66:12-5.

27. Liu Y, Njai RS, Greenlund KJ, Chapman DP, Croft JB. Relationships between housing and food insecu- rity, frequent mental distress, and insufficient sleep among adults in 12 US States, 2009. Prev Chronic Dis 2014;11:E37.

28. National Association of Community Health Centers, Association of Asian Pacific Community Health Organizations, Association OPC, Institute for Alternative Futures. The Protocol for Responding to and Assessing Patients' Assets, Risks, and Experiences (PRAPARE) Published 2016. Available from: www.nachc.org/prapare.

29. Nuruzzaman N, Broadwin M, Kourouma K, Olson DP. Making the social determinants of health a routine part of medical care. J Health Care Poor Underserved 2015;26:321-7.

30. Garg A, Toy S, Tripodis Y, Silverstein M, Freeman E. Addressing social determinants of health at well child care visits: a cluster RCT. Pediatrics 2015;135: e296-e304.

31. Fazalullasha F, Taras J, Morinis J, et al. From office tools to community supports: the need for infrastructure to address the social determinants of health in paediatric practice. Paediatr Child Health 2014; 19:195-9.

32. Page-Reeves J, Kaufman W, Bleecker M, et al. Addressing social determinants of health in a clinic setting: the WellRx pilot in Albuquerque, New Mexico. J Am Board Fam Med 2016;29:414-8.

33. Sandel M, Hansen M, Kahn R, et al. Medical-legal partnerships: transforming primary care by addressing the legal needs of vulnerable populations. Health Aff (Millwood) 2010;29:1697-705. 


\begin{tabular}{|c|c|c|c|c|c|}
\hline \multirow[b]{3}{*}{ Characteristic } & \multicolumn{5}{|c|}{ Worry About Paying Rent or Mortgage } \\
\hline & \multicolumn{2}{|c|}{$\begin{array}{c}\text { In sample } \\
(\mathrm{n}=228,131)\end{array}$} & \multicolumn{2}{|c|}{$\begin{array}{l}\text { Not in sample } \\
(\mathrm{n}=2,151,916)\end{array}$} & \multirow[b]{2}{*}{$P$ Value } \\
\hline & $\mathrm{N}$ & $\%$ & $\mathrm{~N}$ & $\%$ & \\
\hline \multicolumn{6}{|l|}{ Sex } \\
\hline Male & 91,362 & 47.7 & 880,370 & 48.7 & .2232 \\
\hline Female & 136,769 & 52.3 & 1271546 & 51.3 & $<.001$ \\
\hline \multicolumn{6}{|l|}{ Age } \\
\hline 18-24 years & 8,676 & 9.8 & 114,874 & 13.2 & $<.001$ \\
\hline $25-34$ years & 21,207 & 15.9 & 212,688 & 17.5 & $<.001$ \\
\hline $35-44$ years & 28,776 & 17.6 & 262,639 & 16.7 & $<.001$ \\
\hline $45-54$ years & 40,465 & 19.4 & 368,741 & 17.9 & $<.001$ \\
\hline $55-64$ years & 52,992 & 17.8 & 482,443 & 16.1 & $<.001$ \\
\hline 65 and over & 76,015 & 19.5 & 710,531 & 18.6 & $<.001$ \\
\hline \multicolumn{6}{|l|}{ Education } \\
\hline Less than 12 years & 18,415 & 14.1 & 183,753 & 14.9 & $<.001$ \\
\hline Completed 12 years & 64,801 & 28.9 & 621,592 & 28.4 & .0188 \\
\hline Some college or technical school ( $<3$ years) & 62,426 & 30.9 & 582,443 & 30.4 & .0143 \\
\hline College ( 4 years or more) & 82,099 & 26.1 & 752,855 & 25.6 & $<.001$ \\
\hline \multicolumn{6}{|l|}{ Income } \\
\hline Less than $15 \mathrm{k}$ & 20,692 & 9.4 & 220,649 & 11.3 & $<.001$ \\
\hline Greater than $15 \mathrm{k}$ and less than $25 \mathrm{k}$ & 34,117 & 15.9 & 323,625 & 15.3 & $<.001$ \\
\hline Greater than 25 - less than $50 \mathrm{k}$ & 52,042 & 22.5 & 474795 & 21.0 & $<.001$ \\
\hline Greater than $50 \mathrm{k}$ & 91,179 & 39.4 & 800,336 & 37.3 & $<.001$ \\
\hline \multicolumn{6}{|l|}{ Race } \\
\hline Non-Hispanic white & 174,985 & 68.9 & $1,648,547$ & 63.0 & $<.001$ \\
\hline Non-Hispanic black & 26,239 & 17.2 & 163,025 & 10.9 & $<.001$ \\
\hline Non-Hispanic other & 13,076 & 5.4 & 134,593 & 7.7 & $<.001$ \\
\hline Hispanic & 11,268 & 7.5 & 172,007 & 16.8 & $<.001$ \\
\hline \multicolumn{6}{|l|}{ Marital status } \\
\hline Married & 124,472 & 55.1 & $1,125,375$ & 50.0 & $<.001$ \\
\hline Divorced & 31,600 & 11.1 & 299,008 & 10.6 & $<.001$ \\
\hline Widowed & 30,719 & 7.1 & 286,431 & 6.8 & $<.001$ \\
\hline Separated & 4,781 & 2.5 & 45,466 & 2.6 & $<.001$ \\
\hline Never married & 30,718 & 20.3 & 322,395 & 24.6 & $<.001$ \\
\hline Unmarried, with partner & 5,049 & 3.6 & 57,921 & 4.7 & $<.001$ \\
\hline \multicolumn{6}{|l|}{ Number of children } \\
\hline 0 & 166,876 & 63.0 & $1,570,583$ & 62.1 & $<.001$ \\
\hline 1 & 24,293 & 15.1 & 231,474 & 15.3 & .2636 \\
\hline 2 & 21,931 & 13.2 & 204,959 & 13.2 & .829 \\
\hline 3 & 9,438 & 5.6 & 87,057 & 5.7 & .2745 \\
\hline 4 or more & 4,909 & 2.8 & 45,144 & 3.0 & .1448 \\
\hline \multicolumn{6}{|l|}{ Family size } \\
\hline 1 & 60,641 & 13.6 & 558,283 & 12.7 & $<.001$ \\
\hline 2 & 75,663 & 27.8 & 709,384 & 25.2 & $<.001$ \\
\hline 3 & 23,957 & 13.8 & 234,100 & 13.7 & .4744 \\
\hline 4 & 20,564 & 12.9 & 198,828 & 13.2 & .0341 \\
\hline 5 & 9,742 & 6.3 & 94,870 & 6.9 & $<.001$ \\
\hline 6 or more & 6,139 & 4.4 & 63,050 & 5.4 & $<.001$ \\
\hline
\end{tabular}




\begin{tabular}{|c|c|c|c|c|c|}
\hline \multirow[b]{3}{*}{ Characteristic } & \multicolumn{5}{|c|}{ Worry About Paying Rent or Mortgage } \\
\hline & \multicolumn{2}{|c|}{$\begin{array}{c}\text { In sample } \\
(\mathrm{n}=228,131)\end{array}$} & \multicolumn{2}{|c|}{$\begin{array}{l}\text { Not in sample } \\
(\mathrm{n}=2,151,916)\end{array}$} & \multirow[b]{2}{*}{$P$ Value } \\
\hline & $\mathrm{N}$ & $\%$ & $\mathrm{~N}$ & $\%$ & \\
\hline \multicolumn{6}{|l|}{ Reported health status } \\
\hline Excellent & 39,008 & 17.7 & 377,213 & 19.0 & $<.001$ \\
\hline Very good & 75,266 & 32.4 & 693,445 & 31.5 & $<.001$ \\
\hline Good & 70,194 & 31.3 & 660,926 & 31.2 & .4132 \\
\hline Fair & 30,354 & 13.3 & 291,987 & 13.2 & .4565 \\
\hline Poor & 12,766 & 5.0 & 120,394 & 4.8 & .0016 \\
\hline Missing & 543 & 0.3 & 7,951 & 0.4 & \\
\hline \multicolumn{6}{|c|}{ Number of chronic conditions } \\
\hline 0 & 82,846 & 41.5 & 821,662 & 43.0 & $<.001$ \\
\hline 1 & 63,801 & 26.3 & 601,230 & 25.8 & $<.001$ \\
\hline 2 or more & 75,064 & 32.2 & 661,783 & 31.2 & $<.001$ \\
\hline High cost & 25,908 & 15.3 & 250,507 & 15.4 & $<.001$ \\
\hline Routine check-up & 167,589 & 72.3 & $1,558,547$ & 69.4 & $<.001$ \\
\hline No USC & 32,850 & 20.9 & 324,193 & 22.6 & $<.001$ \\
\hline
\end{tabular}

Source: Author analysis of 2011 to 2015 Behavioral Risk Factor Surveillance Survey (BRFSS). Between 2011 to 2015 , 23 states implemented the Social Context Module that included this question. 


\begin{tabular}{|c|c|c|c|c|c|}
\hline \multirow[b]{3}{*}{ Characteristic } & \multicolumn{5}{|c|}{ Worry About Paying Rent or Mortgage } \\
\hline & \multicolumn{2}{|c|}{ Yes $(\mathrm{n}=28,704)$} & \multicolumn{2}{|c|}{ No $(\mathrm{n}=199,427)$} & \multirow[b]{2}{*}{$P$ Value } \\
\hline & $\mathrm{n}$ & $\%$ & $\mathrm{n}$ & $\%$ & \\
\hline \multicolumn{6}{|l|}{ Sex } \\
\hline Male & 9,996 & 42.7 & 81,366 & 48.6 & $<.001$ \\
\hline Female & 18,708 & 57.3 & 118,061 & 51.4 & \\
\hline \multicolumn{6}{|l|}{ Age } \\
\hline $18-24$ years & 1,435 & 10.4 & 7,241 & 9.7 & $<.1346$ \\
\hline $25-34$ years & 3,622 & 18.9 & 17,585 & 15.4 & $<.001$ \\
\hline $35-44$ years & 4,891 & 21.3 & 23,885 & 16.9 & $<.001$ \\
\hline $45-54$ years & 6,845 & 23.4 & 33,620 & 18.7 & $<.001$ \\
\hline $55-64$ years & 6,868 & 16.6 & 46,124 & 18.0 & $<.001$ \\
\hline 65 and over & 5,043 & 9.5 & 70,972 & 21.3 & $<.001$ \\
\hline \multicolumn{6}{|l|}{ Education } \\
\hline Less than 12 years & 4,423 & 24.0 & 13,992 & 12.2 & $<.001$ \\
\hline Completed 12 years & 9,983 & 32.6 & 54,818 & 28.2 & $<.001$ \\
\hline Some college or technical school ( $<3$ years) & 8,700 & 31.1 & 53,726 & 30.8 & .6321 \\
\hline College ( 4 years or more) & 5,543 & 12.1 & 76,556 & 28.6 & $<.001$ \\
\hline \multicolumn{6}{|l|}{ Income } \\
\hline Less than $15 \mathrm{k}$ & 7,197 & 23.9 & 13,495 & 6.7 & $<.001$ \\
\hline Greater than $15 \mathrm{k}$ and less than $25 \mathrm{k}$ & 7,817 & 28.0 & 26,300 & 13.7 & $<.001$ \\
\hline Greater than $25 \mathrm{k}$ and less than $50 \mathrm{k}$ & 6,262 & 21.1 & 45,780 & 22.7 & $<.001$ \\
\hline Greater than $50 \mathrm{k}$ & 4,240 & 15.1 & 86,939 & 43.8 & $<.001$ \\
\hline \multicolumn{6}{|l|}{ Race } \\
\hline Non-Hispanic white & 19,071 & 61.6 & 155,914 & 70.2 & $<.001$ \\
\hline Non-Hispanic black & 4,972 & 22.5 & 21,267 & 16.3 & $<.001$ \\
\hline Non-Hispanic other & 2,228 & 6.0 & 10,848 & 5.3 & .0043 \\
\hline Hispanic & 2,059 & 9.0 & 9,209 & 7.2 & $<.001$ \\
\hline \multicolumn{6}{|l|}{ Marital status } \\
\hline Married & 11,106 & 40.3 & 113,366 & 57.8 & $<.001$ \\
\hline Divorced & 6,576 & 17.4 & 25,024 & 9.9 & $<.001$ \\
\hline Widowed & 3,041 & 6.0 & 27,678 & 7.4 & $<.001$ \\
\hline Separated & 1,549 & 5.7 & 3,232 & 1.9 & $<.001$ \\
\hline Never married & 5,334 & 25.2 & 25,384 & 19.4 & $<.001$ \\
\hline Unmarried, with partner & 985 & 5.0 & 4,064 & 3.4 & $<.001$ \\
\hline \multicolumn{6}{|l|}{ Number of children } \\
\hline 0 & 18,241 & 55.1 & 148,635 & 64.4 & $<.001$ \\
\hline 1 & 4,293 & 18.6 & 20,000 & 14.5 & $<.001$ \\
\hline 2 & 3,511 & 15.4 & 18,420 & 12.8 & $<.001$ \\
\hline 3 & 1,601 & 6.8 & 7,837 & 5.3 & $<.001$ \\
\hline 4 or more & 969 & 3.8 & 3,940 & 2.7 & $<.001$ \\
\hline \multicolumn{6}{|l|}{ Reported health status } \\
\hline Excellent & 2,278 & 8.7 & 36,730 & 19.3 & $<.001$ \\
\hline Very good & 5,675 & 20.4 & 69,591 & 34.7 & $<.001$ \\
\hline Good & 9,100 & 32.8 & 61,094 & 31.1 & $<.001$ \\
\hline Fair & 7,042 & 24.2 & 23,312 & 11.3 & $<.001$ \\
\hline Poor & 4,490 & 13.5 & 8,276 & 3.5 & $<.001$ \\
\hline
\end{tabular}

Source: Author analysis of 2011 to 2015 BRFSS. Between 2011 and 2015, 23 states implemented the Social Context Module that included this question. 